\title{
Analysis of Salivary pH Before and After Intake of Sugary Drinks - An In vitro Study
}

\author{
Azima Hanin S.M'1 ${ }^{1}$ Vishnu Priya. V² and Gayathri. $\mathrm{R}^{3}$ \\ ${ }^{1}$ Saveetha Dental College and Hospitals Saveetha Institute of Medical \& Technical Sciences \\ (SIMATS) Saveetha University Chennai-600077, India \\ ${ }^{2}$ Department of Biochemistry Saveetha Dental College and Hospitals Saveetha Institute of Medical \\ Et Technical Sciences ( SIMATS ) Saveetha University Chennai-600077, India \\ ${ }^{3}$ Department of Biochemistry Saveetha Dental College and Hospitals Saveetha Institute of Medical \& \\ Technical Sciences ( SIMATS ) Saveetha University Chennai-600077, India
}

\section{ABSTRACT}

Diet is a primary aetiological factor for enamel erosion and dental caries. This study was undertaken with the aim of assessing the effect of selected locally available beverages on salivary $\mathrm{pH}$ amongst college students. This study comprised of a study population of 20 subjects divided into two groups. Test beverages were fruit drinks and carbonated beverages. Salivary pH was measured before and after consumption of the sugary drink. Mean difference between baseline $\mathrm{pH}$ and $\mathrm{pH}$ after consuming sugary drinks was calculated. It was found that salivary $\mathrm{pH}$ decreased for all the beverages immediately after consumption. Sharp decline was observed in the $\mathrm{pH}$ value after consumption from 7.15 to 5.5 in the case of carbonated drinks and from 7.15 to 5.45 in the case of fruit drinks. Even when liquid sugars cleared rapidly from the oral cavity, they had a significant cariogenic potential due to the decline in salivary $\mathrm{pH}$. Hence, it is always advised to minimise the consumption of beverages with high sugar content, especially amongst children and young adults to maintain a healthy and caries-free oral cavity.

KEY WORDS: CARBONATED BEVERAGES, FRUIT DRINKS, SALIVARY PH, ENAMEL EROSION, DENTAL CARIES, SUCROSE.

\section{INTRODUCTION}

Oral health is defined by WHO as "being free of chronic mouth and facial pain, oral and throat cancer, oral sores, birth defects such as cleft lip and palate, periodontal disease, tooth decay, and exodontia, and other diseases and disorders that affect the mouth and oral cavity. Dental health has often been viewed in isolation from the general bodily health. History suggests that in the earlier days dental health professionals focused largely

\section{ARTICLE INFORMATION}

*Corresponding Author: vishnupriya@saveetha.com Received 24th July 2020 Accepted after revision 20th Sep 2020 Print ISSN: 0974-6455 Online ISSN: 2321-4007 CODEN: BBRCBA

Thomson Reuters ISI Web of Science Clarivate Analytics USA and Crossref Indexed Journal

\section{Clarivate ${ }_{\text {Analytics }}$ rossef}

NAAS Journal Score 2020 (4.31) SJIF: 2020 (7.728)

A Society of Science and Nature Publication,

Bhopal India 2020. All rights reserved.

Online Contents Available at: http//www.bbrc.in/

Doi: http://dx.doi.org/10.21786/bbrc/13.8/177 on local reparative treatment of oral disease. However, modern-day dentistry places increased emphasis on oral disease prevention and recognizes the importance of the interrelationship between the etiological factors and the health of the teeth and oral tissues along with the general health of the body (Çetinkaya and Romaniuk, 2020). It is well known that a good diet is essential for the development and maintenance of healthy teeth. Diet is a prime aetiological factor for dental caries and enamel erosion. Nutritional status has a huge impact on the development of the teeth and the host's resistance to many oral conditions, including periodontal diseases and oral cancer (Moynihan, 2005).

Saliva plays a major role in the maintenance of oral health. Saliva is one of the most important factors which provides a defensive mechanism in the oral cavity. In a healthy oral cavity, saliva contains glycoproteins, antimicrobial enzymes, and basic electrolytes which protect the oral mucosa. (Humphrey and Williamson, 2001; Renke, 2016). 
Saliva is also important for digestion, bolus formation, taste, protection of the teeth, and antimicrobial effects The normal $\mathrm{pH}$ of saliva ranges from 6.7 to 7.4 but as bacteria in the mouth break down the carbohydrates, they release acids such as lactic acid, butyric acid, and aspartic acid which remarkably reduce the $\mathrm{pH}$ value of saliva. When the $\mathrm{pH}$ level in the oral cavity goes below the critical $\mathrm{pH}$ value $(\mathrm{pH}=5.5)$ the acids present begin to break down the enamel on teeth. The longer the teeth are exposed to low salivary $\mathrm{pH}$ levels, the more likely is the development of dental caries and periodontal diseases (Demirci, Tuncer and Yuceokur, 2010).

Physical state of food plays a very important role in its cariogenic potential. Liquid sugars, such as those found in soft drinks and milk drinks, pass through the oral cavity fairly quickly with limited contact time or adherence to tooth surfaces. It is because of their characteristic readiness to flow, little tendency to disperse, and relatively high incompressibility. Solid sugars get stuck to the teeth surface due to their property of adherence. The longer the tooth is exposed to sugar, the longer the bacteria will act on sugars and produce acid thus leading to the development of dental caries. Sugars present in hard candies, breath mints, lollipops, and popsicles, dissolve slowly and thereby have extended exposure time in the oral cavity (Shaw, 1992) .

Over the last few decades, a trend of declining dental caries in developed countries and an increased caries prevalence in developing countries has been observed. India too has seen the increasing trend similar to that in the latter group of developing countries and the trend might continue in the future as a result of growing globalization (Demirci, Tuncer and Yuceokur, 2010). Globalization in turn is bound to increase the availability of processed and packaged food items. The association between diet, particularly sucrose, and dental caries has been well-documented in many ecological reports. The most susceptible age group to dental caries is the 17-25 years' age group (Demirci, Tuncer and Yuceokur, 2010). Hence, the following study was undertaken with the aim of assessing the effect of selected locally available beverages with high sugar content on salivary $\mathrm{pH}$ amongst college students in the age group of $17-25$ years.

\section{MATERIAL AND METHODS}

The study was carried out in Saveetha Dental College and Hospitals, Chennai, Tamil Nadu. 20 randomly selected undergraduate students Saveetha Dental College and Hospitals, Chennai, were examined. The subjects were selected on the basis of the following inclusion and exclusion criteria.

- Inclusion Criteria:

1. Subjects belonging to 18-22 years of age.

2. Subjects who had a healthy, caries-free, oral cavity with a DMFT score $=0$.

3. Subjects who were not suffering from any systemic illness.
- Exclusion Criteria:

1. Students who did not give informed consent.

2. Students who were using tobacco or alcohol in any form.

3. Subjects who were using any systemic medication at the time of study or in the period of the last 15 days prior to the study.

4. Students who were suffering from any systemic illness.

All the study subjects were similar with respect to their age, dietary habits, oral hygiene measures, and other lifestyle factors which might have a significant effect on the study results. The time of the day was standardized for the collection of all the saliva samples.

Ethical Clearance: Before carrying out the present study, ethical clearance was obtained from the institutional ethical clearance board. Before the start of the study, the purpose and methodology of the study were explained to each of the students and informed consent was obtained from each.

Study Design: Unstimulated salivary sample was collected for each subject two hours after their breakfast. After the collection of baseline salivary samples (before the consumption of test beverage), the study subjects were given a beverage to drink and stimulated saliva samples were collected immediately after test beverage consumption. The study subjects were given two different beverages to drink for subsequent days and subsequent salivary samples were collected. The subjects were divided randomly into two groups : Group A and Group B. Mango fruit drinks were given to Group A consisting of 10 subjects randomly selected and carbonated beverage was given to Group B. $50 \mathrm{ml}$ of the beverages were given to the participants.

Collection of Salivary Samples: Stimulated saliva after consumption of test beverage was collected under resting conditions in a quiet room in order to reduce any stressful conditions. The saliva from the subjects was collected in a sterile calibrated container through a sterile funnel. The salivary $\mathrm{pH}$ was directly estimated using universal $\mathrm{pH}$ indicator paper strips [MERCK $\mathrm{pH}$ indicator paper] for both the samples and compared. The recording of the data was done on a pro forma containing details on the general information, uptake of the selected test beverage of each study subject and group of the subject. To minimize bias or errors in the data, an independent observer, blinded to the study's aim, recorded all the pH values.

\section{RESULTS AND DISCUSSION}

Acidified sugar-containing packaged fruit juices have shown to be cariogenic and erosive in rats (Hans et al., 2016). Juices contain several sugars and non-volatile organic acids. Glucose and fructose are considered to be less cariogenic than sucrose, but dental plaque formed in the presence of a mixture of these two sugars leads to a decrease in the microhardness of the enamel. Packaged 
juices contain excessive amounts of added sugar i.e., sucrose, which is highly cariogenic and increases susceptibility to dental caries. From this study, we observe that there is a significant drop in the mean $\mathrm{pH}$ value $(\mathrm{pH}=5.45)$ after consumption of fruit drink from the baseline $\mathrm{pH}$ value $(\mathrm{pH}=7.15)$ (table 1). These findings are in concordance with literature by Rinki et al and Sudhanshu et al (Sudhanshu, 2010; Hans et al., 2016).

Table 1. Table Showing Group A samples and their salivary $\mathrm{pH}$ before and after consumption of mango drink.

\begin{tabular}{|l|c|c|}
\hline Sample & Before & After \\
\hline Sample 1 & 7 & 6.5 \\
\hline Sample 2 & 7.5 & 5.5 \\
\hline Sample 3 & 7 & 5 \\
\hline Sample 4 & 7 & 6 \\
\hline Sample 5 & 7 & 6 \\
\hline Sample 6 & 7 & 6.5 \\
\hline Sample 7 & 7 & 5 \\
\hline Sample 8 & 7.5 & 5 \\
\hline Sample 9 & 7 & 5 \\
\hline Sample 10 & 7 & 5.45 \\
\hline Mean & 7.15 & \\
\hline
\end{tabular}

Graph 1: This Bar Graph shows Group A samples and their salivary $\mathrm{pH}$ before and after consumption of mango drink. $\mathrm{X}$ - axis denotes the samples and $\mathrm{Y}$ - axis represents the $\mathrm{pH}$ of saliva. Blue colour represents the $\mathrm{pH}$ of saliva before consumption of mango drink and Orange represents the $\mathrm{pH}$ of salivary sample after consumption. From this graph it is evident that there is a significant decrease in the $\mathrm{pH}$ of the saliva samples after consumption of mango drink.

\section{GROUP A}

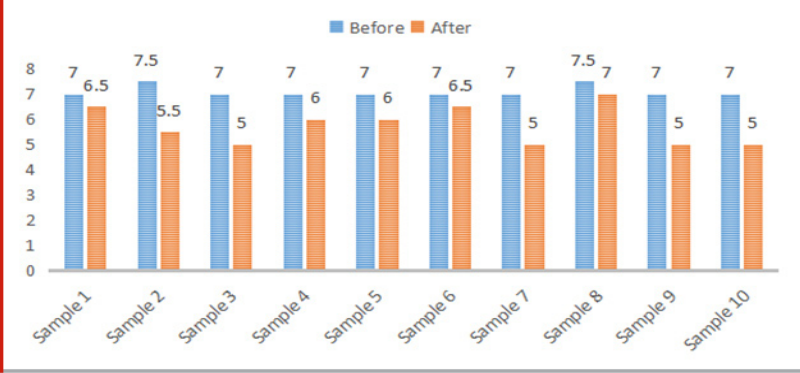

The probable reason for the immediate drop in salivary $\mathrm{pH}$ after consumption in this study could be that the intrinsic acidity of fruit juices enabled it to be more able to combat salivary buffers. There may be a prolonged fall in the oral cavity $\mathrm{pH}$ due to the increased buffering capacity of fruit juices \&t the fluidness consistency of the pulp of the fruit. Though the amounts of fruit drinks consumed by the population may be insignificant, the presence of immature enamel, inability to clear the retentive substrate, and inadequate neuromuscular coordination and along with the deleterious methods of consumption, makes them susceptible to dental erosion
(Lee and Wrolstad, 1988). Beverage markets have seen increased consumption of aerated drinks by teenagers and children, who account for $65 \%$ of total sales. Literature reveals that peer pressure, pleasure, and taste are reasons that lead children to consume these drinks (Nielsen and Popkin, 2004; Vartanian, Schwartz and Brownell, 2007).

Table 2. Table Showing Group B samples and their salivary $\mathrm{pH}$ before and after consumption of carbonated beverage.

\begin{tabular}{|l|c|c|}
\hline Sample & Before & After \\
\hline Sample 1 & 7.5 & 5.5 \\
\hline Sample 2 & 7 & 6 \\
\hline Sample 3 & 7 & 5 \\
\hline Sample 4 & 7.5 & 6 \\
\hline Sample 5 & 7.5 & 5 \\
\hline Sample 6 & 7 & 5.5 \\
\hline Sample 7 & 7 & 5 \\
\hline Sample 8 & 7 & 6.5 \\
\hline Sample 9 & 7 & 5.5 \\
\hline Sample 10 & 7 & 5 \\
\hline Mean & 7.15 & 5.5 \\
\hline
\end{tabular}

Graph 2: This Bar Graph shows Group B samples and their salivary $\mathrm{pH}$ before and after consumption of carbonated beverage. $\mathrm{X}$ - axis denotes the samples and $\mathrm{Y}$ - axis represents the $\mathrm{pH}$ of saliva. Blue colour represents the $\mathrm{pH}$ of saliva before consumption of carbonated beverage and Orange represents the $\mathrm{pH}$ of salivary sample after consumption. From this graph it is evident that there is a significant decrease in the $\mathrm{pH}$ of the saliva samples after consumption of carbonated beverages.

\section{GROUP B}

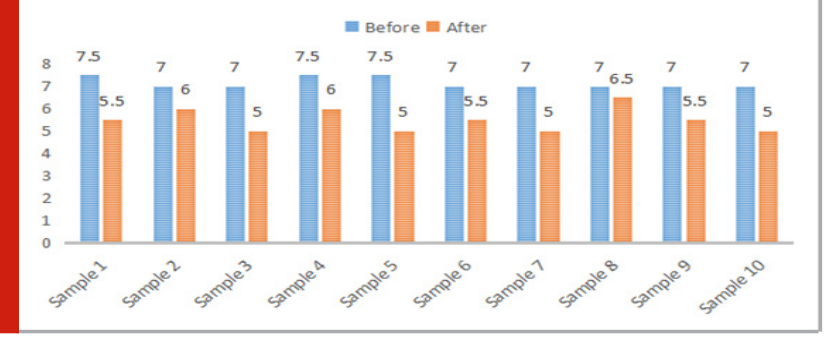

These changes have major implications for dental health. The number of sugar-containing beverages consumed and late-onset of oral hygiene measures correlate positively with plaque accumulation and caries prevalence in the primary dentition (Mattos-Graner et al., 1998; Habibian et al., 2001; Jerkovic et al., 2009). Soft drinks contain not only sugars but also different nonvolatile organic acids, and maybe a primary extrinsic etiological factor in the development of dental erosions (Rugg-Gunn et al., 1998; Moazzez, Smith and Bartlett, 2000; Al-Dlaigan, Shaw and Smith, 2001). Various host factors like salivary buffering capacity, and $\mathrm{pH}$, can influence the extent of 
dental erosion and demineralization (Tahmassebi and Duggal, 1996; Millward et al., 1997).

In the present study, the carbonated beverage contained carbonated water, sugar, caffeine, colouring agents, and acidity regulator as its ingredients. The quantity of sugar added is $10.6 \mathrm{~g} / 100 \mathrm{~g}$ or 11 teaspoonfuls of sugar in $300 \mathrm{~mL}$ of the drink. It caused an instant decrease in salivary $\mathrm{pH}$ from 7.15 to 5.5 . This is in agreement with the study proposed by Hans et al and Demir et al. This may be probably due to the fact that the carbonated beverage has increased intrinsic acidic content and sugar content in its composition which is responsible for its high cariogenic and demineralizing or erosive potential (Balappanavar, Sardana and Singh, 2013).

\section{CONCLUSION}

The erosive potential of sugary drinks must be dependent upon the immediate effect of the drink, the protective effect of saliva, the amount of residual drink after swallowing, the actual amount of sugar consumed, and the frequency of consumption. A single acidic attack is of minor importance but if repeated, the ability of saliva to buffer may decrease. Hence the main concern is the frequent usage of sugary drinks over time. If consumption is frequent enough and there are few or no protective factors, then this may be an aggressive factor that increases the caries prevalence in people. Within the limits of this study, it was observed that there was a significant decrease in $\mathrm{pH}$ of saliva after the consumption of both mango drink and carbonated beverage. Awareness camps, seminars, health education programs may be conducted to create awareness on deleterious effects of sugary drinks in oral cavity.

\section{ACKNOWLEDGEMENTS}

We sincerely thank Saveetha Dental College for rendering full support for my study.

\section{Conflict of Interest: Nil}

\section{REFERENCES}

Al-Dlaigan, Y., Shaw, L. and Smith, A. (2001) 'Dental erosion in a group of British 14-year-old school children Part II: Influence of dietary intake', British Dental Journal, pp. 258-261. doi: 10.1038/sj.bdj.4800943a. Balappanavar, A. Y., Sardana, V. and Singh, M. (2013) 'Comparison of the effectiveness of 0.5\% tea, 2\% neem and $0.2 \%$ chlorhexidine mouthwashes on oral health: a randomized control trial', Indian journal of dental research: official publication of Indian Society for Dental Research, 24(1), pp. 26-34.

Çetinkaya, H. and Romaniuk, P. (2020) 'Relationship between consumption of soft and alcoholic drinks and oral health problems', Central European journal of public health, 28(2), pp. 94-102.

Demirci, M., Tuncer, S. and Yuceokur, A. A. (2010) 'Prevalence of Caries on Individual Tooth Surfaces and its Distribution by Age and Gender in University Clinic Patients', European Journal of Dentistry, pp. 270-279. doi: $10.1055 /$ s-0039-1697839.

Habibian, M. et al. (2001) 'Dietary habits and dental health over the first 18 months of life', Community dentistry and oral epidemiology, 29(4), pp. 239-246.

Hans, R. et al. (2016) 'Effect of Various Sugary Beverages on Salivary pH, Flow Rate, and Oral Clearance Rate amongst Adults', Scientifica, 2016, p. 5027283.

Humphrey, S. P. and Williamson, R. T. (2001) 'A review of saliva: Normal composition, flow, and function', The Journal of Prosthetic Dentistry, pp. 162-169. doi: 10.1067/mpr.2001.113778.

Jerkovic, K. et al. (2009) 'Differences in oral health behaviour between children from high and children from low SES schools in The Netherlands', Community dental health, 26(2), pp. 110-115.

Lee, H. S. and Wrolstad, R. E. (1988) 'Apple Juice Composition: Sugar, Nonvolatile Acid, and Phenolic Profiles', Journal of AOAC INTERNATIONAL, pp. 789-794. doi: 10.1093/jaoac/71.4.789.

Mattos-Graner, R. O. et al. (1998) 'Association between Caries Prevalence and Clinical, Microbiological and Dietary Variables in 1.0 to 2.5-Year-Old Brazilian Children', Caries Research, pp. 319-323. doi: 10.1159/000016466.

Millward, A. et al. (1997) 'Continuous monitoring of salivary flow rate and $\mathrm{pH}$ at the surface of the dentition following consumption of acidic beverages', Caries research, 31(1), pp. 44-49.

Moazzez, R., Smith, B. G. N. and Bartlett, D. W. (2000) 'Oral $\mathrm{pH}$ and drinking habit during ingestion of a carbonated drink in a group of adolescents with dental erosion', Journal of Dentistry, pp. 395-397. doi: 10.1016/ s0300-5712(00)00020-8.

Moynihan, P. (2005) 'The interrelationship between diet and oral health', Proceedings of the Nutrition Society, pp. 571-580. doi: 10.1079/pns2005431.

Nielsen, S. J. and Popkin, B. M. (2004) 'Changes in beverage intake between 1977 and 2001', American journal of preventive medicine, 27(3), pp. 205-210.

Renke, W. (2016) 'Saliva and Dental Caries', Dental Caries, pp. 59-69. doi: 10.1007/978-3-662-474501_3.

Rugg-Gunn, A. J. et al. (1998) 'Comparison of Erosion of Dental Enamel by Four Drinks Using an IntraOral Applicance', Caries Research, pp. 337-343. doi: 10.1159/000016469.

Shaw, L. N. (1992) 'Primary preventive dentistry, 3rd edition', Journal of Dentistry, p. 224. doi: 10.1016/03005712(92)90086-r.

Sudhanshu, S. (2010) 'EFFECT OF FRESH FRUIT JUICES ON pH OF DENTAL PLAQUE', Annals and essences of dentistry, pp. 36-40. doi: 10.5368/aedj.2010.2.4.36-40. pdf.

Tahmassebi, J. F. and Duggal, M. S. (1996) 'Comparison of the Plaque $\mathrm{pH}$ Response to an Acidogenic Challenge in Children and Adults', Caries Research, pp. 342-346. doi: 10.1159/000262340.

Vartanian, L. R., Schwartz, M. B. and Brownell, K. D. (2007) 'Effects of soft drink consumption on nutrition and health: a systematic review and meta-analysis', American journal of public health, 97(4), pp. 667675. 